\title{
Macrothink
}

\section{School Age Gender Gap in Reading Comprehension}

\author{
Christy L. Pagal \\ Department of Education \\ Cebu City, Philippines \\ Jhon Kevin A. Mirafuentes (Corresponding author) \\ Aletheia University \\ New Taipei City, Taiwan \\ E-mail: reycamion21@gmail.com \\ Quennie C. Ypanto \\ Department of Education \\ Cebu City, Philippines
}

Received: April 18, 2017 Accepted: June 2, 2017 Published: June 6, 2017

doi:10.5296/jad.v3i2.11079 URL: https://doi.org/10.5296/jad.v3i2. 11079

\begin{abstract}
Students' reading comprehension was found to be one of the major concerns with all teachers worldwide. It is essential to optimize students' performance in all courses. Yet, we claimed that gender, and reading attitudes and practices could influence reading comprehensibility. We utilized descriptive-correlational design of quantitative research. Descriptive design was used to obtain the attributes of students' reading attitudes and practices. Moreover, we used a correlational design to determine the relationship or association between and among attributes and their level of reading comprehension skills. We found out that students have a positive attitude towards reading when reading materials are educational and entertainment. In terms of the significant relationship between reading attitudes and practices, results reveal that reading attitude does not always affect reading practices. In terms of the relationship between student's reading attitudes and practices and their levels of reading comprehension skills, student's reading attitudes and practices have no significant relationships to all levels except between their reading attitudes and their comprehension skills in the Inferential Level. Lastly, in terms of the significant difference between male and female students' reading comprehension skills, there is a statistical difference in the Literal and Evaluative Levels between the male and female. Thus, reading comprehension skills vary in these two levels. On the other hand, they showed no statistical difference in the Inferential and Critical Levels between the male and female. Therefore, the Literal and Evaluative Levels of male and female to reading comprehension skills are due to their reading attitudes and practices individually.
\end{abstract}

Keywords: school age, gender gap, reading comprehension 


\section{Introduction}

Reading comprehension is a widespread topic in academic researches. Some researchers considered this subject matter as cliché, overused, hackneyed. However, we cannot deny the fact that even in this modern time one of the vivid and top ranked problems in the Philippine education system is learners' reading comprehension. Teaching areas across the nation are mixed together with students who experience the reading comprehension frustration every day. Without comprehension, reading is just uttering the words without understanding them. The words on the page have no meaning. This is the reason, reading comprehension skills are so important. Without them, the reader is not in a position to gather any information and use it to efficiently function and enjoy the richness of life. Henceforth, the study claimed that gender, reading attitudes and practices, regardless of students' socio-economic status and age, could influence reading comprehensibility.

In each successive assessment, the Progress in International Reading Literacy Study (PIRLS) has consistently found that fourth grade girls have much higher average reading achievement than boys in most countries, and in the 2011 results continue this pattern. For the PIRLS 2011 countries at fourth grade, at sixth grade, and the benchmarking participants, it shows girls' average achievement, boys' average achievement, and the difference between the two averages. Also, the Philippine Statistics Authority reported the recent 2013 Functional Literacy, Education, and Mass Media Survey (FLEMMS) that results show the functional literacy rate among females $(97.0 \%)$ is higher than males $(96.1 \%)$. This means that females are better readers than males. Which could be concluded that females are much capable to read and write compared with males. In the local aspect, based on the result of the Philippine Informal Reading Inventory (Phil. IRI) conducted by the English Teachers in Esperanza National High School to the students, $49 \%$ of the total population is below average reader in terms of reading comprehension, and $28 \%$ of which are males. This end result is quietly distressing. Almost half of the population has below average reading comprehension level. Tamayosa discussed as cited by Pilayan (2014) that reading is the primary step to gain knowledge. Thus, proficient readers have greater possibilities to be efficacious in school. Luz as cited by Pilayan (2014) emphasized as well, that the key to learning is better reading skills. The appreciable gap between male and female literacy scores has been the source of much attention in the study. The study on reading comprehension has attempted to look into the comprehension levels do males and females differ from literal, inferential, critical, and applied as well as reading attitudes and practices of both genders using the Philippine Informal Reading Inventory (Phil. IRI). The study differentiated the school age gender gap in reading comprehension of the Esperanza National High School students. Specifically, it (1) determined students' attributes in terms of (a) Attitudes, (b) Practices towards reading, and (c) Levels of Reading Comprehension; (2) found out if there was a significant relationship between (a) students' reading attitudes to reading practices, (b) reading practices to learners' reading comprehension, and (c) reading attitudes and practices to learner's reading comprehension; (3) found out if there was a significant relationship between students' reading attitudes and practices to their reading comprehension skills; and (4) found out if there was a significant difference between the male and female levels of reading comprehension in terms of literal, inferential, critical, and evaluative. 


\section{Theoretical Framework}

In the world of teaching, a learner is the core and key participant in the learning process. Educators keep on seeking remedies to enhance the teaching and learning process. Numerous learning theories explained how learners learned. For this, the researchers dig for significant learning theory that would cater and help in quenching the learners thirst for learning particularly in terms of reading comprehension for reading without understanding is nothing.

The study was anchored on Social Constructivism theory of Vygotsky (1934). According to Social Constructivists, learning is contoured by our prejudices, experiences, the time in which we live, and both physical and mental maturity. Ozer (2004) said that when a learner is motivated, the learner exercises his or her own will, determination, and action to gather selective information, convert it, formulate hypotheses, test these suppositions through applications, interactions or experiences, and to draw provable conclusions. In other words, reading attitudes seem to emanate from perceptions acquired from people's reading history and experience (Guthrie \& Greaney, 1991). Moreover, Constructivism is an approach in education that claims that a learner would be better in understanding when information is constructed by himself. As stated by the Constructivist theories, learning is social advancement that involves language, real world situations and interaction and collaboration among learners.

Consequently, culture greatly affects the social context of the learner. Social constructivism emphasizes the importance of culture and context in understanding what occurs in society and constructing knowledge based on this understanding (Kim, 2001). As noted by Lawal (2008 as cited by Awe, 2014), the bedrock of the reading culture is the awareness of the tremendous values of reading in the modern world that is increasingly complex and insecure. According to constructivist theorist, for learning to occur, the child first makes contact with the social environment on an interpersonal level and then internalizes this experience. The past perception and current experiences influence the child, who then constructs new concept. Vygotsky (1934), known for his theory of social constructivism, believes that learning and development is a collaborative activity and that children are cognitively developed in the context of socialization and education. The perceptual, attention, and memory capacities of children are transformed by vital cognitive tools provided by culture, such as history, social context, traditions, language, and religion. In other words, cultures, practices and attitudes of the society, that surround the learner, play a significant role in the cognitive development of the child. This is because the learners are curious and actively involved in their own learning and the discovery and development of new understanding or schema.

Shabani, K., Khatid, M. and Ebadi, S. (2010) additionally discussed in their study that examined the instructional implications of Vygotsky's (1978) seminal notion of Zone of Proximal Development, originally developed to account for the learning potential of children, and investigates ZPD applications to the concept of teacher professional development. Specific attempt has been made to see how a number of assets at the teacher's disposal namely diary writing, peer and mentor collaboration, action research, practicum and TESOL discourse can serve as scaffolds to affect the progression of ZPD in language teachers.

Meanwhile, social interaction holds a vital role in the cognitive development as Vygotsky (1934) believed strongly that the community plays a central role in the process of "making 
meaning." The attitude and the practices of the scaffolds in the learner's environment have an immense impact on the cognitive development of the child's learning. Vygotsky placed more emphasis on social contributions to the process of development. Unquestionably, thus, the most important learning of the child occurs through social interaction with a skillful tutor or adult who is considered as scaffolds of the child's learning.

One of the principles of Vygotsky's theory of learning is the More Knowledgeable Other (MKO) where in someone who has a better understanding or a higher ability level than the learner, with respect to a particular task, process, or concept (Mcleod, 2014). Although the implication is that the MKO is a teacher or an older adult, this is not necessarily the case. Many times, a child's peers or an adult's children may be the individuals with more knowledge or experience. In fact, the MKO need not be a person at all. Some companies, to support employees in their learning process, are now using electronic performance support systems. Electronic tutors have also served in educational settings to facilitate and guide students through the learning process. The key to MKOs is that they must have (or be programmed with) more knowledge about the topic being learned than the learner does.

To add, the second essential principle of Vygotsky's work is the Zone of Proximal Development (ZPD). In this concept, distance between the actual development of a child as determined by the independent problem solving, and the level of potential development as determined through problem solving under adult guidance or in collaboration with more peers suggests that cognitive development is limited to a certain range at a particular age. However, with the help of social interaction, such as assistance from a mentor, students can comprehend concepts and schemes that they cannot know on their own. The roles of the adults as scaffolds with different attitudes and practices play a significant part in the learning process. This is an important concept that relates to the difference between what a child can independently achieve and what a child can achieve with guidance and encouragement from a skilled partner. As emphasized in this principle the ZPD as the area where the most sensitive instruction or guidance should be given - allowing the child to develop skills they will then use on their own - developing higher mental functions. As claimed by the researchers and was as well supported by Vygotsky (1934) that an interaction with peers is an effective way of developing reading comprehension skills. In the classroom setting, this theory suggests that teachers use cooperative learning exercises where less competent children develop with help from more skillful peers - within the ZPD. For this the group work tasks have been given importance.

Moreover, culture gives the child the cognitive tool needed for development this is clearly underscored by the social constructivist. Adults such as parents and teachers are conduits for the tools of the culture, including language. The tools the culture provides a child include cultural history, social context, and language. Today they also include electronic forms of information access. We call Vygotsky's brand of constructivism social constructivism because he emphasized the critical importance of culture and the importance of the social context for cognitive development. Thus, reading acquisition is one of the learned skills as the learner learns from his environment. Hence, we can say that the child's own reading attitudes and practices play a role in his or her own reading comprehension skill acquisition. Similarly, McKenna et al. (1995) opined that it seems that cultural beliefs are another cradle for the 
incubation of negative or positive attitudes towards reading. Thus, Samuels (2011) as cited by Cabana (2014) asserted that if learning is to read effectively is a journey toward ever-increasing ability to comprehend texts, then teachers are the tour guides, ensuring that students stay on course, pausing to make sure they appreciate the landscape of understanding. In the same vein, Mathewson (2004), in his model of reading attitudes, asserted that a positive reading attitude does not guarantee actual reading behavior. He suggested an additional element that is the intention to read or continue reading. He argued that measuring whether attitudes are positive or negative is of little consequence: one's attitude may be positive but one may lack the intention to read, resulting in non-reading behavior being exhibited. The amount and depth of a reader's world knowledge vary as do other individual characteristics. Readers vary in the skills, knowledge, cognitive development, culture, and purpose they bring to a text (Narvaez, 2002). Mathewson's model of reading attitudes features external motivators and internal states as components that influence one's intention to read. Hence, this model brings in "prevailing feelings about reading, action readiness for reading and evaluative beliefs about reading" as component factors in the reading attitudes. Moreover, readers also read in particular ways depending on the purpose for reading. Another individual difference that exists in readers is motivation. Motivation can influence the interest, purpose, emotion, or persistence with which a reader engages with text (Pardo, 2004). More motivated readers are likely to apply more strategies and work harder at building meaning. Less motivated readers are not as likely to work as hard, and the meaning they create will not be as powerful as if they were highly motivated. Therefore, it is vital to recognize the important position of "attitude" when we seek to cultivate readers (Lukhele, 2013).

Undeniably, cognitive development leads to reading comprehension. This is on cognition to comprehension. A reader's cognitive development causes that reader to evaluate text in different ways (Pardo, 2004). This is now on the interaction between the reader and the reading material. The learner as part of the society with the culture, with the reading attitude of the scaffold and their roles, who are considered as the more knowledgeable other and the ones who observed the ZPD of the child, their practices he or she learned concepts and skills from his or her environment and one of the skills is the reading comprehension skill (Mirafuentes, Lopez \& Diano, 2015). Moreover, reading comprehension involves one's knowledge of the world, which may be culturally-based and culturally biased. Pardo (2004) added that comprehension is affected by a reader's culture, based on the degree to which it matches with the writer's culture or the culture espoused in the text. Classroom implications of the schema-theoretic view of reading for English for Foreign Language or English as a Second Language reading pedagogy are discussed with techniques suggested for bringing about reader-centered EFL or ESL reading (P. L. Carrell \& J. C. Eisterhold, 1983).

These levels are literal (reading the lines), inferential (reading between the lines), critical (reading beyond the lines) and creative/evaluative reading levels (Villamin, 2001). These levels were defined by the score obtained from the levels of comprehension assessment tool (Mirafuentes, 2014). Literal reading comprehension skill is the ability of the reader to identify the specific details from the printed text (Villamin et al., 2001). To read correctly one must have to uncover the meaning of each vocabulary word in the context and be acquainted with the grammatical relationships among the words. Extracting the superficial meaning of 
the sentence, involves reconstructing the writer's exact thoughts.

Mirafuentes, Lopez and Diano (2015) noted that inferential reading comprehension skill is the ability of the learner to predict without the given detailed information from the text, the same as true with the critical reading comprehension skill. Critical reading comprehension skill is the ability of the reader to evaluate ideas and details from fact and opinion and detect the author's purpose in writing the given text. And the last reading comprehension kill is evaluative; this is the ability of the reader to deduce the central point of the manuscript based on judgment with criteria. Guzman, et al. (1796) stated that in the material thought above, one learns how to "read the lines" in order to obtain the literal level meaning of the sentence. Therefore, according to Mirafuentes, Lopez and Diano (2015) reading is not this simple for many things a writer says have to be inferred. To paraphrase what the poet once said: if one really wants to be knowledgeable about what a man wants to express, listen not to what he says, but what he does not say. If the reader infers and makes inferences, then he or she is able to easily compare and distinguish things critically.

Villamin et al. (2001) aforesaid that as the reader reads, he passes judgment on the quality, consistency, relevance, accuracy and intellectual worthiness of the material. Hence, the reader must read critically, a reader must read very carefully at times slowly, analyze objectively and weight the author's intent, his point of view, the way he expresses ideas, his unique style of presenting the material, the appropriateness of the devices he utilized to achieve his purpose Mirafuentes, Lopez and Diano (2015). With this a reader must go beyond the literal and inferential. A reader must go beyond the details found in the surface of the text for beyond the superficial meaning lies a new learning.

Hence, teachers leave no stone unturned in encouraging and engaging the learners in their reading comprehension. For reading texts will trigger understanding. Learners should make sense of the written text prepared for them, to make a great foundation of themselves in the yet to come challenge they are to take. Wolf (1993) discussed the variety of reader and text variables involved in comprehension, and she echoed Bernhardt's (1991) claim that there is not "one true comprehension, but a "range of comprehension." Thus, however, this veracity is not supported by some learners, specially the boys. The educators have observed that in terms of reading, boys usually show unwillingness to read than girls.

Gender stereotyping is one of the cited causes of this occurrence. This is a notion about gender that refers to things and instances that normally for females and males (Morris, 2007). This is on the concept of appropriate characteristics and behavior or traits that are for males and females. This occurrence is said to be part of the child's development. Researchers observed that as the child comprehends the idea of gender differences, he or she will actively seek stereotypes of sex-appropriate behavior in daily interaction with others.

Morris (2007) added that gender stereotyping affects views about opposite occupational roles between males and females and this, in turn, affects curriculum choice in schools. Boys were commonly exposed to industrial arts as an introduction to technology, while girls were trained in home management. This concept on the career path assignments was a clear indication that the education planners held traditional views about the roles of both sexes.

Beyond that, the concept on gender stereotyping does not wholly starts in the school age 


\section{MInstitute ${ }^{\text {Macrothink }}$}

learners. Morris (2007) emphasized that gender stereotyping does not begin in adolescence when students choose subjects on the basis of their perception of certain subjects as gendered. Learners start going to school with gender appropriate behavior ingrained. From birth, parents treat boys and girls differently; girls are dressed in pink, boys in blue. They are given gender differentiated toys - dolls for girls, and trucks and guns for boys - and are expected to behave differently. Boys are told that boys do not cry and girls are encouraged to be quiet and obedient.

Young men prefer technical and science-oriented subjects, while young women typically go for caring, or arts/humanities/social sciences subjects. Furthermore, Morris (2007) exposed explanations on this instance, boys and girls tend to enjoy and pursue different subjects because there are innate differences between males and females; differences in cognitive style; a masculinized educational environment that values the learning styles of boys over girls; and gender stereotyping, or differential constructions of gender, among pupils and teachers. Literacy and English are often constructed as 'naturally female' due to their 'feminine' curriculum content. Girls, then, may find the study of English to be affirming to their constructions of femininity, while boys may find it challenging to their constructions of masculinity.

The study gives an assumption as a clue to the current study why males have the lesser number of readers compared to girls because reading and language is gender appropriate to females. Males show unwillingness to read and low performance in reading because, reading is considered a girl thing from the males' point of view which is affected by the norm of the society they are in. The choices of girls and boys may therefore reflect both the desire of individuals to align themselves with apparently gender-appropriate subjects, and the appeal of a (gendered) subject curriculum to an individual with gendered interests.

Therefore, gender and passage content play a big role in reading comprehension. This conclusion was proven by Martinez (2013) in her research on Analysis of the Effect of Content Familiarity and Gender on English as a Foreign Language Reading Comprehension by Spanish University Students. Martinez (2013) asserted that sexuality characteristics and subject matter awareness were found to have to do with the large number of learners reading comprehension. The male learners are found to perform better than girls in their reading comprehension performance in familiar and an unfamiliar text. These results appear to support Bügel and Buunk's (1996) and Al-Shumaimeri's $(2005,2006)$ as cited by Martinez (2013) findings that male learners shows off greatly than female learners in comprehending gender-neutral texts. The type of text used is one explanation on the gender effect found in the study. Informative texts were utilized and males read more informative literature than female students. Aside from that readers' interest may also explains the supremacy of male students in Martinez' (2013) study. Brantmeier (2003) added, in her study on Does gender make a difference? Passage content and comprehension in second language, which findings revealed significant interactions between readers' gender and passage content with comprehension on both assessment tasks. The results provided evidence that subject matter familiarity has a facilitating effect on second language reading comprehension by gender at the intermediate level of Spanish language instruction.

Martinez (2013) cited one of the reasons of the males' superiority in reading and that is male 
learners' reading interest. The male students show interests in a particular topic and reveal enough knowledge on such topics. Aside from that, the male learners also show minimum knowledge on a topic which they are not interested. Hence, they still understand a vast area in reading different type of texts. On the females reading performance conversely, the female learners show interest in a certain topic which is familiar to them, and show little interest to unfamiliar reading texts. When the reading text is unfamiliar therefore, the females' reading performance decline.

As the study proves, content familiarity or subject awareness appreciably influence a large number of comprehensibility to the learners, therefore the more familiar the reading text the better the reading comprehension performance. The findings tell us that the content familiarity aids in the comprehension performance of male and female students. These conclusions come in view to support the schema theory of reading, and research on second language (L2) reading (Carrell, 1991). Based on the schema theory of reading, the idea of the reading text helps in the reading comprehension during the encryption and decryption development through giving an idea to which the readers could contrast and put in knowledge. However, good readers generally read anything they can find and so they will read whatever materials are available (Grabe, 1991).

Bartlett, L. (1990) and Carrell (1984) revealed that an individual's memory is made up of above average organization of scheme, every single of which captures a human knowledge in all certain things or happenings. These representations represent the universal information that helps in the grasping of discussions and passages as well as real-life events. For schema theory is a presumption on how information is represented and about how representation aid in the utilization of information in certain ways. The ideas or pieces of information saved in the schemata affect the understanding of new ideas grasp in the environment (Rumelhart, 1980; Carrell, $1981 \&$ An, 2013). If the latest idea is inadequate, the reader creates implications based on the selected schema to fill in the lacking parts. Therefore, the conduct of the study determined the association between and among students' reading attitudes and practices and levels of reading comprehension.

\section{Research Methodology}

Researchers utilized the descriptive-correlational design of quantitative research. Descriptive research was used to obtain information concerning the current attributes of students' reading attitudes and practices, which were utilized to describe the gap that existed between the students' gender and level of reading comprehension skills. Moreover, the study used correlational design in to determine the relationship or the association between and among attributes and level of reading comprehension skills. Purposive non-probability sampling technique was used when we were interested in the normality/typicality of the units like Grades 8 students. Henceforth, it allowed them to compare the findings from a study using typical case sampling with other similar samples. There were 56 students who served as the respondents of the study.

To make the conduct of the research successful and peaceful, one must follow the protocol. A permit from the School Head of Esperanza National High School was secured to conduct the study with the premise that there is no class disruption at the conduct of the study. After which, the questionnaires were distributed which this is to pre-examine the learners' reading 
attitudes and practices. Also, simple percentage was utilized to describe the students' attributes in terms of reading attitude, practices, and their levels of reading comprehension skills. Pearson Product-Moment Correlation $r$ was used as this study aimed to determine the relationship between students' reading attitudes and practices. Hence, ANOVA or analysis of variance was as well applied to measure the strength of the association between variables. The researchers further used of $p$-values to determine the statistical significance in all hypotheses formulated in this study.

To determine the students' level of comprehension skills, the scores in each category were examined. To interpret the gathered data, we used of the standard academic performance of the $\mathrm{K}$ to 12. The Department of Education (Philippines) in the Enhanced Basic Education Curriculum (levels of performance) through the curriculum guide in English. Accordingly, each of the content standards is assessed according to the DepEd Order No. 31, s. 2012: Beginning (B) level denotes student's reading skill is struggling which scored from $74 \%$ below. Developing (D) denotes reading skill which is just enough and needs assistance from the more knowledgeable other and scored $75 \%$ to $79 \%$. Approaching proficiency (AP) denotes the student's reading skill with a little assistance from the teacher or peers and which scored from $80 \%$ to $84 \%$. Proficiency (P) suggests that the students can now read independently and scored $85 \%$ to $89 \%$. Advanced (A) suggests students' reading skill is spontaneous and scored $90 \%$ above.

\subsection{Ethical Considerations}

Ultimately, we adhered to the ethical standard described by the Institutional Review of the Board (IRB) of the University of the Visayas, Cebu City, Philippines. Hence, we guaranteed the protection of the student's rights. Confidentiality and privacy of the gathered data, personal data and answer sheets of the minor student respondents were done to safeguard and ensure the right to privacy of the participants. Since, the study was designed to minimize risks and maximize benefits to participants, it would surely help the students boost their interest in reading especially if they are going to participate well in the conduct of the study. We made sure that there is an expression of agreement which is a simplified assent form since the learners are 12 under 15 in the process of the study. Out of respect of children as developing persons, they should be provided with essential information and would let them comprehend the objective of the study and that gathered data from respondents were for research purposes. Repeatedly, upholding individuals' rights to confidentiality and privacy is a central tenet of every researcher work.

\section{Results and Discussion}

This chapter deals with the presentation, analysis, and interpretation of data that were obtained from the reading attitudes and practices questionnaire and the levels of reading comprehension worksheet dole out in Esperanza National High School, Matalom, Leyte, answered by the Grade 8 students enrolled in the academic year 2016-2017.

This chapter has two parts, the first part is the Grade 8 students' attributes in terms of attitudes and practices towards levels of reading comprehension, and the second part is the result and discussion of the significant difference between student's gender and their level of reading comprehension skills. 
4.1 Part I

Table 1 shows the top three responses of the students' attribute in terms of attitude towards reading. Where, 60 students took the test and answered the question, "If you read, why do like to read?".

Table 1. Student's attribute in terms of their attitude toward reading

\begin{tabular}{llll}
\hline If you read, why do you like to read? & Frequency & Percent & Rank \\
\hline To learn something/it's educational & 60 & $100 \%$ & 1 \\
For motivation & 55 & $91.7 \%$ & 2 \\
For I have to(requirement of the teacher) & 53 & $88.3 \%$ & 3.5 \\
I get attach to characters & 53 & $88.3 \%$ & 3.5 \\
\hline
\end{tabular}

For the rank 1, 100\% of the Grade 8 students answered "to learn something, or because reading is educational", this means that all of the Esperanza National High School Grade 8 students show positive attitude towards reading. As the result show, $100 \%$ or all Grade 8 students like reading because reading is educational- through reading, they learn something. For the rank 2, which $91.7 \%$ of the Grade 8 students answered reading is for motivation, this means that majority of the Esperanza National High School Grade 8 Students see reading as for something that can make them inspire or interested. For the rank 3 , which $83.3 \%$ of the Grade 8 students answered they read because they have to, they are required by the teacher and they get attached to characters. Majority of the Grade 8 students read because their teacher compels them to read. All of the grade 8 students like reading because the students see reading as informative and helpful in their studies. This implies that all of the Grade 8 students have positive attitude towards reading. The students see reading as beneficial. The students see reading as educational; they can learn something through it. With this, the students will most likely improve their academic performance not just in English subject but also in other subjects, for reading is a requirement in all subject areas and the students possess positive attitude in reading. With this, teachers must provide and assign text to learners for them to read. Assigning the students, may help push the students' will to read, and would yield on the most wanted outcome of the students- their interest in reading. The result contradicted the finding of Awe (2014) in her study about the Relationship between Reading Attitudes and Reading Comprehension Performance of Secondary School Students in Kwara State, Nigeria that revealed that majority of the students sampled had negative attitudes towards reading. This finding implies that extensive reading attracted less positive attitudes from the students than intensive and literary reading. However as Lawal (2008) opines an individual who lack the awareness of the values of reading cannot develop positive attitude to reading. Likewise, Petscher (2010) and Seitz (2010) corroborate the assertion that learners' positive attitude to reading are highly critical sign for their high scores in reading comprehension performance.

In fact, as Mathewson (1994) said that intention to read is proposed as the primary mediator between attitude and reading. All other moderator variables (extrinsic motivation, 
involvement, prior knowledge, and purpose) are viewed as affecting the attitude reading relationship by influencing the intention to read. Mathewson (1994) added that reading is influenced by attitude. The attitude towards reading will influence the intention to read, in turn influencing reading behavior. As students' positive reading attitude became stronger, they reported reading more for enjoyment and reading more diverse types of reading materials such as magazines, fiction, nonfiction books, and newspapers because they wanted to. On the contrary, as students expressed more negative attitudes toward reading, they reported reading less for enjoyment and reading less diverse types of reading materials. It is thus evident that when students have positive attitudes toward reading, they are more likely to engage in reading related activities voluntarily and do so for more intrinsic reasons (Lim, Bong, \& Yeon, 2015).

Therefore, if students have high and positive attitude towards reading, chances are they can increase comprehensibility and increase academic performance in school. With this, teacher must utilize the Grade 8 students' positive attitude towards reading to maximize the students time in school through reading. The teacher must assign reading text and would let the students read books; stories and initiating them more in reading for this would most likely give the students' appreciation and give more in themselves in reading.

Table 2 shows the top three responses of the students' attribute in terms of attitude towards reading. Where, 60 students took the test and answered the one question, "If you don't read, why not?"

Table 2. Student's attribute in terms of their attitude toward reading

\begin{tabular}{llll}
\hline If you don't read, why not? & Frequency & Percent & Rank \\
\hline Like other activities better & 32 & $53.3 \%$ & 1 \\
Rather spend time with my friends & 25 & $41.7 \%$ & 2 \\
Too busy no time & 22 & $36 \%$ & 3 \\
\hline
\end{tabular}

For the rank 1, which $53.3 \%$ of the grade 8 students answered, that the reason they do not read is because they like other activities, this means that majority of the Esperanza National High Grade 8 students like other activities, like playing or hanging out with their friends or playing on anything available rather than reading. This further means that, great numbers of student do not read because they prefer to do something else. These students show a pessimistic view in reading that would cause the reading performance of the students decline. For the rank 2, which $41.7 \%$ of the Grade 8 students answered that the reason they do not read is they would rather spend time with their friends, this means that some of the Esperanza National High School Grade 8 students like spending time with friends rather than reading. Spending and wasting their time in school and in their house with their friends. For the rank 3, which $36 \%$ of the Grade 8 students answered that the reason they do not read is they are too busy no time, this means that some of the Esperanza National High School Grade 8 students do not have time to read because they are too busy. 


\section{Macrothink}

This implies that majority of the students when they do not read; they like other activities than reading, and they would rather spend time with friends. The students prefer to be with their friends doing nothing, like chit chat, playing games, and some other activities. This end result that most numbers of Grade 8 students in Esperanza National High School show a pessimistic view in reading. This result is the reason why even nowadays, reading comprehension is still a problem in school because the students prefer to do other things than reading. Even how much the teacher urges them to read during their free time, still, the students would prefer doing something else. Spending time with friends doing non-academic tasks really would make their reading comprehension decline. With this result, if the students prefer doing something else than reading, this would make their performance in English and in other subject areas decline. The school administrators would find more remedies to cater the diminishing reader in the classroom. The curriculum would be poorly implemented because students reading comprehension would be left behind. These instances would mean that teachers must motivate the students more about reading on their free time. Teachers must give emphasis in motivating them to read every day. Teachers must ignite the students to read. Teachers must not leave stone unturned to boost the students' intention to read.

In fact, as Mathewson (1994) said that the intention to read is proposed as the primary mediator between attitude and reading. All other moderator variables (extrinsic motivation, involvement, prior knowledge, and purpose) are viewed as affecting the attitude reading relationship by influencing the intention to read. Mathewson (1994) added that reading is influenced by attitude. The attitude towards reading will influence the intention to read, in turn influencing reading behavior.

Furthermore, Early (2011) affirms that students' attitudes towards reading are influenced by all the people that they come in deal with on a regular basis. At school, the learners converse to teachers and other classmates or students around their age with different attitudes towards reading. Hence, teachers are one of the significant factors in the learning process. From the result, if the students have a pessimistic view in reading, chances are, they can decrease comprehensibility the same as true with their academic performance. We concluded that the very reason of the low performance of the Grade 8 students in reading comprehension is that they prefer doing non-academic tasks than reading.

Table 3 shows the top three responses of the students' attribute in terms of practices towards reading. Where, 60 students took the test and answered the one question, "What do you like to read?"

Table 3. Students attribute in terms of their practices towards reading

\begin{tabular}{llll}
\hline What do you like to read? & Frequency & Percent & Rank \\
\hline Entertainment & 52 & $86.7 \%$ & 1 \\
Newspaper & 50 & $83.3 \%$ & 2 \\
Video games & 49 & $81.7 \%$ & 3.5 \\
Comics & 49 & $81.7 \%$ & 3.5 \\
\hline
\end{tabular}


For the rank 1, which $86.7 \%$ of the grade 8 students answered, that they like to read entertainment, this means that majority of the Esperanza National High Grade 8 students practice to read something entertaining. These are reading materials that would make them enjoy when they read. These are the readings that talk about their "idols", singers, dancers, actors and actresses. Greater number of Grade 8 students prefers to read entertainment readings; this would mean that they are going to have a positive attitude towards reading depending on the reading materials they prefer to read. The Grade 8 students would most likely enjoy reading if entertainment reading materials would be provided for them.

For the rank 2, which $83.3 \%$ of the Grade 8 students answered, that they like to read on newspaper, this means that almost all of the Esperanza National High School Grade 8 students like to read news from newspapers or issues happen in their environment. These are the current or timely happenings in the child's environment. For the rank 3 , which $81.7 \%$ the Grade 8 students likes to read video games and comics, this means that majority of the Esperanza National High School Grade 8 Students like to read something on games and short playful conversations in comics.

This result implies that Grade 8 students prefer to read reading materials that is on entertainment section or in reading materials issued for very recent times. These are reading materials about the students' favorite famous and trending artists, singers, dancers and commonly mentioned and shown in the social media and in the television. The students like reading the hottest issues and readings that they commonly hear in the environment. With this, the classroom must provide these kinds of reading materials. Just as mentioned by Rathe and Blakenship (2006) revealed that most students are fascinated in reading materials on best seller list and those that are commonly mentioned and considered trending in the social media. Therefore, the classroom must be equipped with these kinds of reading materials, mini libraries in the classroom must be made with materials that ignites the learners to read. This result would strengthen the idea of providing reading centers in the classroom. Providing avenues for student students would mean improving their academic performance.

From the end result, if the students prefer to read reading in the entertainment section, chances are the students would read much if these type of reading materials will be available in the environment where he/she is in every day. The learners' reading comprehensibility will most likely increase however this could not guarantee an increase of academic performance for entertainment readings are not educational. From this result, this outcome may be the reason why the result of the students' level of reading comprehension examination is quite low, none of them mastered any levels of reading comprehension because of the type of text they have read and answered in the worksheet. The students find the readings in the worksheet not entertaining for them so interest and comprehensibility declined. Therefore, teachers must choose reading texts that entertain yet educational to hook readers, thus, attract attention.

Table 4 shows the top three responses of the students' attribute in terms of practices towards reading. Where, 60 students took the test and answered the one question, "What do you like to read about?". 
Table 4. Students attribute in terms of their practices towards reading

\begin{tabular}{llll}
\hline What do you like to read about? & Frequency & Percent & Rank \\
\hline Historical figures & 54 & $90 \%$ & 1 \\
$\begin{array}{l}\text { People/characters my age who are wrestling with tough } \\
\text { issues like drug abuse, corruption, or crime }\end{array}$ & 47 & $78.3 \%$ & 2 \\
Musicians & 44 & & \\
\hline
\end{tabular}

For the rank 1, which $90 \%$ of the grade 8 students answered, that they like to read about historical figures, this means that majority of the Esperanza National High Grade 8 students have a practice in reading about figures that formerly exist. These are reading materials about history or related to the past or evolution. For the rank 2, which $78.3 \%$ of the Grade 8 students answered, they like to read about people/characters or personalities of their age who are wrestling with tough issues like drug abuse, corruption, or crime, this means that majority of the Esperanza National High School Grade 8 students like to read about materials that deal about personalities of their age who have experienced and struggled societal issues. These are the reading materials that they have seen in the news or documentaries that are the featured of their age, and are dealing with rampant issues in the society. For the rank 3, which $73.3 \%$ of Grade 8 students answered that they like to read about musicians, this means that not all but majority of the Esperanza National High School Grade 8 students like to read about music makers. These are reading materials about their idol singers, or performers that they have seen and idolized in the television or in the internet.

The presented result means that the Esperanza National High School Grade 8 students consider reading materials that talks about the past, about the beginning of something, how did particular occurrence started, or all of the things, and personages contributed on a particular thing that is still looked up to until the present - readings that would make them realize and know the record of the interesting past. With the proliferation of well-written historical fiction on the shelves today, one can find a tale to connect students to nearly any historical event at any grade level. Reading that type of narrative literature while studying an era of history, students will be able to deepen their comprehension of the texts by getting to know the real or fictional characters in the book and understand why some historical figures acted the way they did.

This result implies that reading material really bears significant motivation to them to read. Hence, teachers must provide with reading materials that would relate to their age so that the time when they spent with their friends would also be the time that they read for they have something in common to read on. Just as mentioned by Rathe and Blakenship (2006) reveals that most students are fascinated in reading materials on best seller list and those that are commonly mentioned and considered trending in the social media. Just as Martinez (2013) asserted that content familiarity is found to have significant effect on student's overall comprehension of the text. Familiar text boosts the learners' interest in reading. Hence, teachers must provide materials which appeals to the learners' interest.

Mathewson (1994) posited that classroom environments must have well-stocked libraries, 


\section{Ml Macrothink}

magazines, reading tables, and areas with comfortable chairs for this would enhance student's intentions to read. Mathewson (1994) added that favorable attitudes towards reading sustain intention to read and reading as long as readers continue to be satisfied with reading outcomes. Therefore, if students have positive attribute towards reading materials of their preference, chances are they can increase comprehensibility however, it could not guarantee an increase in their academic performance.

Table 5 shows summary of the students score in terms of their levels of reading comprehension skills. Where, 60 students took the test of 8 items in every level of reading comprehension (literal, inferential, critical, and evaluative).

Table 5. Levels of reading comprehension

\begin{tabular}{|c|c|c|c|c|c|c|c|c|}
\hline \multirow[b]{2}{*}{ Score } & \multicolumn{2}{|c|}{ Literal } & \multicolumn{2}{|c|}{ Inferential } & \multicolumn{2}{|c|}{ Critical } & \multicolumn{2}{|c|}{ Evaluative } \\
\hline & F & $\%$ & F & $\%$ & F & $\%$ & F & $\%$ \\
\hline $\mathbf{0}$ & 0 & 00.0 & 3 & 5.0 & 1 & 1.7 & 4 & 6.7 \\
\hline 1 & 4 & 6.7 & 11 & 18.3 & 10 & 16.7 & 7 & 11.7 \\
\hline 2 & 4 & 6.7 & 20 & 33.3 & 10 & 16.7 & 15 & 25.0 \\
\hline 3 & 12 & 20.0 & 9 & 15.0 & 15 & 25 & 11 & 18.3 \\
\hline 4 & 19 & 31.7 & 11 & 18.3 & 16 & 26.7 & 11 & 18.3 \\
\hline 5 & 12 & 20.0 & 4 & 6.7 & 6 & 10.0 & 9 & 15.0 \\
\hline 6 & 7 & 11.7 & 2 & 3.3 & 2 & 3.3 & 3 & 5.0 \\
\hline 7 & 2 & 3.3 & 0 & 00.0 & 0 & 00.0 & 0 & 00.0 \\
\hline 8 & 0 & 00.0 & 0 & 00.0 & 0 & 00.0 & 0 & 00.0 \\
\hline Total & 60 & 100.0 & 60 & 100.0 & 60 & 100.0 & 60 & 100.0 \\
\hline
\end{tabular}

For the score of 8 , the data showed that none of the Grade 8 students got a perfect score in all levels of reading comprehension. This simply means that none of the Esperanza National High School Grade 8 students mastered all levels of reading comprehension. None of the Grade 8 students mastered the literal, inferential, evaluative, and critical level of reading comprehension since all the 60 Grade 8 students got no perfect score in the aforementioned level. For the score of 7, only 2 of the 60 students who took the test in the literal level were able to get a score. And none of students scored in the inferential, critical and evaluative. This means that only a small number of students have nearing mastery in the literal level and none in the next levels of reading comprehension. For the score of 6-the passing score- 7 students scored in the literal level, 2 students in the inferential level, 2 in the critical level and 3 in the evaluative level, this means that only 16 out of 60 students passed the test and this represents a small portion of the entire population.

The results have shown that only a small number of students passed the levels of reading comprehension examination. And none of the Esperanza National High School Grade 8 
students mastered any levels of reading comprehension and have not acquired any level of reading comprehension skills. Medes (SEAMEO, 2012) reported that the students at these levels struggle with their understanding; prerequisite and fundamental knowledge and/or skills have not been acquired or developed adequately to aid understanding. This end result readily implies that the students badly need assistance in reading even in the literal level. Therefore, if students have not acquired any level of reading comprehension chances are, they cannot perform well not just in the reading classes but also in any other academic classes. Therefore, reading interventions must be conducted to aid students' reading ability; thus, consequently making their comprehension headway.

Table 6 calculates the degree and the significance of the two factors: reading attitudes and practices of the Grade 8 students of Esperanza National High School.

Table 6. Relationship between students' reading attitudes and practices

\begin{tabular}{|c|c|c|c|c|c|}
\hline Reading Attitude & $r_{x y}$ & P-value & Interpretation & & Significance \\
\hline Reading Practices & 0.029 & 0.825 & $\begin{array}{l}\text { Negligible } \\
\text { Correlation }\end{array}$ & Positive & Not Significant \\
\hline
\end{tabular}

The table provides the significance and the degree of relationship between the reading attitudes and practices of the respondents. A Pearson product-moment correlation was run to determine the significance and to identify the degree of the relationship. As computed, there was a positive correlation between the attitudes and practices; however, the correlation coefficient $r_{x y}(0.029)$ is so close to zero, thus, the correlation is just negligible. This means that student's reading attitudes somehow has an effect on their reading practices but this association is unimportant. Since the $\mathrm{p}$-value $=0.825$ is greater than the level of significance 0.05 , therefore, the null hypothesis is accepted, such that, there is no statistical significant relationship between students reading attitudes and their reading practices. This means that the relationship was due not by any circumstance but only by chance.

This result implies that the reading attitude may affect reading practices in some way. There are circumstances that a student will read not because he or she loves to read but he or she has to read. Hence, it is not all the time that the reading attitude affects reading practices. With this, motivation to read and appropriate reading materials would be best for these students. The teacher must not get tired of assigning the students and providing interesting reading materials to boost the students interest to build further positive attitude towards reading and that would lead the students to have a reading practice.

Just as significant, as Rundell (1994) claimed that the agent for prior knowledge or schema is the learners' environment. The environment of the child is the main contributor of the child's cognitive development. That leads to the way he or she perceives things especially ideas or concepts he or she reads. That is, the reader, the text, the teacher, and the classroom community are all involved in the construction of meaning. Therefore, if the students' reading attitude does not affect greatly their reading practices, the reason why they have a low score 


\section{Ml Macrothink}

in the levels of reading comprehension is because of their preference of the reading material they have read.

Table 7 deals with the relationship between students' reading attitudes and practices to each level of student's reading comprehension skills.

Table 7. Relationship between students' reading attitudes and practices and student's levels of reading comprehension skills

\begin{tabular}{lllll}
\hline Between & $\boldsymbol{r}_{\boldsymbol{x}}$ & $\mathbf{p}$-value & Interpretation & Significance \\
\hline Literal & & & & \\
Attitude & 0.029 & 0.828 & Negligible Positive Correlation & Not Significant \\
Practice & 0.200 & 0.126 & Negligible Positive Correlation & Not Significant \\
\hline Inferential & & & & \\
Attitude & -0.376 & 0.003 & Slight Positive Correlation & Significant \\
Practice & 0.179 & 0.170 & Negligible Positive Correlation & Not Significant \\
\hline Critical & & & & Not Significant \\
Attitude & -0.234 & 0.072 & Negative Slight Correlation & Not Significant \\
Practice & -0.108 & 0.410 & Moderate Positive Correlation & \\
\hline Evaluative & & & & Not Significant \\
Attitude & -0.227 & 0.082 & Negligible Negative Correlation & Not Significant \\
Practice & 0.121 & 0.358 & Negligible Positive Correlation & \\
\hline
\end{tabular}

Table 7 revealed the relationship between students' reading attitudes and practices and students' levels of reading comprehension skills. A Pearson product -moment correlation was run to determine the significance and to identify the degree of the relationship. In the literal level, there is no significant relationship in the literal level of comprehension to the student's reading attitudes $(r=0.029, \mathrm{p}$-value $=0.828)$ and $\operatorname{practices}(r=0.200, \mathrm{p}$-value $=0.126)$. This means that, the practices and reading attitude of the child do not affect the literal level of understanding of the child.

On the other hand, in the inferential level, reading attitude tells that reading attitude $(r=$ $-0.376, \mathrm{p}$-value $=0.003)$ is significant in the inferential level and reading practices $(r=0.179$, p-value $=0.170$ ) is not significant. This means, that reading attitude affects the inference skills of a learner. However, the critical and evaluative level of reading comprehension result tells that there is no significant relationship of reading attitude $(r=-0.234 ;-0.227, \mathrm{p}$-value $=$ $0.072 ; 0.082)$ and practices $(r=-0.108 ; 0.121$, p-value $=0.410 ; 0.358)$ of the child in his or her critical and evaluative level of comprehension.

The result is inconsonance with the studies of Lawal (2008), Petscher (2010), and Awe (2014) that showed that a very high and positive significant relationship existed between reading attitudes and reading comprehension performance of the students. Hence, students need to be 


\section{Macrothink}

equipped with rich vocabulary which engenders good performance in reading comprehension task. These reading scholars have also established that learners who are slow at comprehension will almost possibly develop a feeling of dislike for books and this will most likely prevent them from having adequate practice in reading. This will invariably result in poor standards of reading. It naturally follows then that less than the one with positive attitude. By implication too, he is not likely to perform well in reading comprehension task.

Overall, student's reading attitudes and practices had no significant relationships to all levels except between their reading attitudes $(r=-0.376$, p-value $=0.003)$ and their comprehension skill in terms of inferential. Villamin et al. (2001) mentioned that without appropriate and adequate knowledge, the reader cannot make necessary inferences, and without inferences there is no real readings, Thus the inferential level involves the readers' ability to determine facts and relationships, the depth and breadth of their prior knowledge and experience (Mirafuentes, Lopez, \& Diano (2015). Villamin et al. (2001) added that any inadequacy in these factors may lead them to make incorrect and illogical inferences. Pressley (2006) additionally contends that prior knowledge plays an important role permitting the generation of inferences required to understand the text. Likewise, Nuttall (1996) stressed that implicit inferential comprehension can be enhanced by the activation of schemata. This, however, will not explain the overall test results of the Grade 8 students in reading comprehension skills which claim that most of them did not acquire the necessary skills to achieve good performance in the reading comprehension skills test, but must not set aside the fact that attitudes and practices in reading plays an important part in the reading comprehension skills of the child. Thus, teachers still have to inculcate and promote the necessary moves to encourage students to read during their vacant time to enhance and develop themselves positive attitudes and practices towards reading.

\subsection{Part II}

This portion calculates the significant difference between student's gender and their level of reading comprehension skills as to literal level (reading the lines, the inferential level (reading between the lines), the critical level (beyond the lines) and the evaluative or creative level (application). 
Table 8. Significant difference between gender and levels of reading comprehension in terms of literal, inferential, critical, and evaluative

\begin{tabular}{lllllll}
\hline Gender And Literal & $\begin{array}{l}\text { Sum of } \\
\text { Squares }\end{array}$ & df & $\begin{array}{l}\text { Mean } \\
\text { Square }\end{array}$ & F & P-value & Significance \\
\hline Between Groups & 19.817 & 1 & 19.817 & 11.248 & 0.001 & Significant \\
Within Groups & 102.183 & 58 & 1.762 & & & \\
$\quad 122.000$ & 59 & & & & \\
$\quad$ Total & 3.202 & 1 & 3.202 & 1.528 & 0.221 & Not Significant \\
Inferential Between Groups & 121.531 & 58 & 2.095 & & & \\
Within Groups & 124.733 & 59 & & & & \\
$\quad$ Total & 2.138 & 1 & 2.138 & 1.080 & 0.303 & Not Significant \\
\hline Critical Between Groups & 114.846 & 58 & 1.980 & & & \\
$\quad$ Within Groups & 116.983 & 59 & & & & \\
$\quad$ Total & 22.893 & 1 & 22.839 & 10.189 & 0.002 & Significant \\
\hline Evaluative Between Groups & 130.011 & 58 & 2.242 & & & \\
$\quad$ Within Groups & 152.850 & 59 & & & & \\
$\quad$ Total & & & & & & \\
\hline
\end{tabular}

The table illustrates the significant difference between the male and female levels of reading comprehension in terms of literal, inferential, critical, and evaluative. A One-Way ANOVA was applied to determine if there is a statistical difference between student's gender and the four levels of reading comprehension skills. Based on the computations, there is a statistical difference in the literal $(\mathrm{F}=11.248, \mathrm{P}$-value $=0.001)$ and in the evaluative levels $(\mathrm{F}=10.189$, $\mathrm{P}$-value $=0.002)$ between the male and female Grade 8 students. While showed no statistical difference in the inferential $(\mathrm{F}=1.528, \mathrm{P}$-value $=0.221)$ and in the critical level $(\mathrm{F}=1.080$, P-value $=0.303$ ) between the male and female students. In the literal and evaluative comprehension skills, male readers seemingly found to be better reader than females. In the study on gender differences in achievement test performance at the college level, Doolittle and Welch (1989) found notable gender differences for items associated with specific passages, reporting that males scored higher with science-oriented passages than females. The reading materials that we used were about the superstitious belief, the history of Frisbees, and giant squids and its body parts' functions. These reading texts involved scientific and historical non-fictions.

To support, PIRLS (2006) research data showed that at their fourth year of schooling, girls had significantly higher reading achievement than boys in all countries except in Spain and Luxembourg. In these two countries, the difference between sexes was not significant (Mullis et al., 2007). This goes to show that in the present study, not all the time that female students excel in all reading comprehension levels. In the literal level, males performed better than females. For the past decades, it has been argued, debated through academic researches that females are far better than males in terms of reading achievement. The male students seem to have performed significantly better than the female students in their comprehension 
performance of gender-neutral texts. They tended to score higher on both the familiar and the unfamiliar texts. These results appear to support Bügel and Buunk's (1996) finding that male students performed significantly better than female students in comprehending gender-neutral texts.

In providing such support, however, the results appear to be in contrast to a view that has become almost commonsensical: the assumption that female students are in general more successful in language learning than their male counterparts (Sunderland, 2000). Based on the result of Progress International Reading Literacy Study (PIRLS, 2006) as reported by Arellano (2013), female students have a higher achievement in literal reading in all European countries. Literal reading involves ideas that are simply, directly and explicitly stated in the text (Villamin et al., 2001). The average student male can understand textual structure (literal reading) and gets general information with some problems. He misunderstands some specific information and has serious problems to deduce meaning from the context (general to specific) (Arellano, 2013). In other words, males are specifics or inclined to specific and explicit details.

Clearly, gender differences tend to be bigger when the information is implicit in the text and tend to be smaller when the information is explicit in the text. However, it seems that boys have serious difficulties to find implicit information. Evidently, females perform better than males in reading and this fact is widespread and significant. But, we must consider that large gender differences do not imply poor male achievement in reading. In Finland, which is the leading European country on average reading score, it is not that males do poorly in reading, their scores are above the international average and the highest among males in Europe, but rather that females score exceptionally well. The present study, however, contradicts the finding of Arellano (2013) that males have serious difficulties in the evaluative reading. This reading level is the ability to find the main idea.

To add, in the past decades researching about gender differences which were tested with different variables, females stayed in its threshold who is better readers than males. In nearly all of the countries and benchmarking participants, girls outperformed boys in 2011, and there has been little reduction in the reading achievement gender gap over the decade (Mullis et al., 2012).

Inversely, there is no statistical difference in the inferential and in the critical level between the male and female students. In other words, whatever attitudes and practices they may have individually, they do not warrant they have a good comprehension performance because they have not even mastered the literal level of comprehension skill. There is no better reader in terms of genders, male and female readers have their individual reading attitudes and practices that lead them to understand and comprehend reading texts. Thus, accordingly, in these two levels, both genders have found to be no better readers.

Additionally, based on the result, male and female performances on reading comprehension were affected by its reading materials and text content that is why their attitude towards reading is positive. In the study conducted by Al-Shumaimeri (n.d.), findings reveal that content familiarity has a facilitating effect on reading comprehension. Reading materials affect reading comprehensibility by both genders depending on their individual interest and motivation to read. The results of the study clearly showed that both genders preferred to 
read more on educational reading materials yet entertaining. Furthermore, however, in the given questionnaires on what they preferred to read, students preferred to read on educational yet entertaining. Any subjects in school are all educational. It is all up to the teacher how to deliver the instruction to make the teaching-learning process significant and entertaining. The sexuality characteristics and subject matter awareness were found to have to do with the large number of learners reading comprehension. The male learners are found to perform better than girls in their reading comprehension performance in familiar and an unfamiliar text (Martinez, 2013). Thus, content familiarity or subject awareness appreciably influence a large number of comprehensibility to the learners, therefore the more familiar the reading text the better the reading comprehension performance. Therefore, reading materials must be considered.

\section{Conclusion}

Based on the findings, the researchers arrived to the conclusion that reading attitude does not greatly affect reading practices of the child; therefore, positive reading attitude would not always guarantee a good reading practice. Though reading attitude and practice do not affect entirely to the levels of reading comprehension skill of the child, the significant difference in the literal and evaluative levels of male and female to reading comprehension skills is due to their reading attitudes and practices individually. Furthermore, one possible explanation for the superiority of the male students in the study is that males and females may not have been equally matched in their interests to the reading text. Although they were at the same instruction level, the male students seem to have been more proficient readers than their female counterparts. Selection of reading materials is important. Thus, however, there should be a balance of reading materials, both male-oriented and female-oriented. Therefore, teachers can make use of reading materials that suit to the needs and genders, which consequently reinforce students' attitudes and practices towards reading. Thus, accordingly, the more the reader uses his or her interest the more proficient reader he or she becomes.

\section{References}

Alcantara, J. S. (2012). Status of the Reading Comprehension of the Second Year (Unpublished thesis, University of the Visayas, Cebu City).

Al-Shumaimeri, Y. A. N. (n.d.). Gender Differences in Reading Comprehension Performance in Relation to Content Familiarity of Gender-Neutral Texts. King Saud University.

An, S. (2013). Schemata Theory in Reading. Theory and Practice in Language Studies (Vol. 3. Np. 1, pp. 130-134). Finland: ACADEMY PUBLISHER. https://doi.org/10.4304/tpls.3.1.130-134

Arellano, M. D. C. (2013). Gender Difference in Reading Comprehension Achievement in English as a Foreign Language in Compulsory Secondary Education. Tejuelo, (17), 67-84.

Awe, B. M. T. (2014). Relationship between Reading Attitudes and Reading Comprehension Performance of Secondary School Students in Kwara State, Nigeria. Review of Arts and Humanities, 2(2), 203-215. American Research Institute for Policy Development.

Barrel, G. (2012). Boys' Reading Commission. Retrieved from June 24, 2016, 
https://www.literacytrust.org.uk/assets/0001/4056/Boys_Commission_Report.pdf.

Bartlett, L. (1990). Teacher Development through Reflective Teaching. In J. C. Richards and D. Nunan (eds.)., Second Language Teaching Education (pp. 202-214). CUP.

Bernhardt, E. B. (1991). Reading development in a second language. Norwood, NJ: Ablex.

Bohol, J. (2015). Students' Reading Comprehension and Reading Habits Through Teacher-Developed Instructional Module (Unpublished thesis, Southern Leyte State University, Sogod Souther Leyte).

Boote, D. N., \& Beile, P. (2005). Purpose of the Literature Review. Retrieved June 3, 2016, from http://www.library.cqu.edu.au/tutorials/litreviewpages/.

Brantmeier, C. (2003). Does gender make a difference? Passage content and comprehension in second language reading. Reading in a Foreign Language, 15(1). Washington University.

Cabana, J. (2014). Facilitating Reading Comprehension Using Reading Aloud and Shared Reading Through Inductive Method (Unpublished thesis, Southern Leyte State University, Sogod southern Leyte).

Carrell, P. L. (1984), Schema Theory and ESL Reading: Classroom Implications and Applications. The Modern Language Journal, 68, 332-343. https://dx.doi/10.1111/j.1540-4781.1984.tb02509.x

Carrell, P. L., \& Eisterhold, J. C. (1983). Schema Theory and ESL Reading Pedagogy. TESOL Quarterly, 17, 553-573. https://doi.org/10.2307/3586613

Chinwonno, A., \& Vongkrachang, S. (2015). CORI: Explicit Reading Instruction to Enhance Informational Text Comprehension and Reading Engagement for Thai EFL Students. Retrived from June 12, 2016.

Costley, K. (2012). An Overview of the Life, Central Concepts, Including Classroom Applications of Lev Vygotsky. Retrieved from February 7, 2016 http://files.eric.ed.gov/fulltext/ED529565.pdf.

DepEd. (2012). K to 12 Learning Area Team for Language and Multi-literacies. Philippines Normal University: May 4, 2012.

Doolittle, A., \& Welch, C. (1989). Gender differences in performance on a college-level achievement test (ACT Reserch Rep. Series 89-9). Iowa City, IA: American College Testing Program.

Early, J. (2012). Leisure Reading Habits: Students Attitudes Toward Their in School Reading Compared to Out of School Reading. Retrieved from March 12, 2014,fromhttp://fisherpub.sjfc.edu/cgi/viewcontent.cgi?article=1196\&context=education_ET D_masters.

Edradan, G. (1997). An Appraisal of the Reading Comprehension Difficulties in Filipino of Elementary Grade Pupils in Burauen North and South District, Leyte Division: Proposed 
Measures for Improvement (Unpublished thesis, University of the Visayas, Cebu City).

Grabe, W. (1991). Current Development in Second Language Reading Research. TESOL Quarterly, 25(3), 375-406. https://doi.org/10.2307/3586977

Guthrie, T., \& Greaney, V. (1991). Literacy acts. In R. Barr, M. L. Kamil, P. B. Mosenthal, \& P. D. Pearson (Eds.), Handbook of reading research (Volume II, pp. 68-96). New York: Longman.

Guzman, M. K. et al. (1976). Developing Reading and Language Skills for College University of the East. Publishers Association of the Philippines, INC. Sp. No. 74.

Henry, J. (1995). If not now. Developmental Reading in the College Classroom. Potsmouth, NH: Heinemann.

Kilinc , H. H., \& Yenen, E. T. (2015). Investigation of Students' Reading Anxiety with Regards to Some Variables. Retrieved June 29, 2016, http://files.eric.ed.gov/fulltext/EJ1088663.pdf.

Kim, B. (2001). Social Constructivism. In M. Orey (Ed.), Emerging perspectives on learning, teaching, and technology. Retrieved January, 2016, from http://projects.coe.uga.edu/epltt/.

Lawal, R. A. (2008). Cultivating the Culture of Reading in Nigeria (A Paper delivered at the Fountain University, Osogbo, Osun State. February $4^{\text {th }}$ ).

Lim, H. J., Bong, M., \& Yeon, K.W. (2015). Reading Attitude as a Mediator Between Contextual Factors and Reading Behavior. Teachers College Record (Vol. 117, 010303, Teachers College. Columbia University, pp. 0161-4681).

Loveless, T. (2015). Girls, Boys, and Reading. Retrieved May 24, 2016 from http://www.brookings.edu/research/reports/2015/03/24-gender-gap-loveless.

Lukhele, B. B. S. (2013). Exploring relationships between reading attitudes, reading ability and academic performance amongst primary teacher trainees in Swaziland. Reading and Writing Journal of the Reading Association of South Africa, 4(1). https://doi.org/10.4102/rw.v4i1.28

Macleod, S. (2014). Lev Vygostky. Retrieved from Jan. 5, 2016. Retrieved from www.simplypsychology.org/vygotsky.html.

Martinez, A. C. ( 2013). Analysis of the Effect of Content Familiarity and Gender on English as a Foreign Language Reading Comprehension by Spanish University Students University of Oviedo. $\quad$ Retreived from January 4, 2016, http://www.ugr.es/ portalin/articulos/PL_numero21/5\%20\%20Ana\%20Cristina.pdf.

Mathewson, G. C. (2004). Model of Attitude Influence upon Reading and Learning to Read. In R. B. Ruddell \& N. J. Unrau (eds.), Theoretical Models and Processes of Reading, pp. 1431-1461, International Reading Association, Newark, DE. https://doi.org/10.1598/0872075028.50 
McKenna, M. C., Kear, D. J. \& Ellsworth, R. A. (1995). Children's attitudes toward reading: A national survey. Reading Research Quarterly, 30(4), 934-956. https://doi.org/10.2307/748205

Mirafuentes, J. K. (2014). The Reading Comprehension Skills Using SQ3R Method (Unpublished thesis. University of the Visayas, Cebu City).

Mirafuentes, J. K., Lopez, N., \& Diano, F. (2015). The Reading Comprehension Skills Using SQ3R Method (University of the Visayas Journal of Research, Vol. 9)

Morris, J. (2007). Gender Stereotyping. Retrieved from February 4, 2016. From http://uwispace.sta.uwi.edu/dspace/bitstream/handle/2139/6339/Jeanette\%20Morris3.pdf?seq uence $=1$

Mullis, I. V. S., et al. PIRLS (2007). International Report: IEA'S Progress in 2016 International Reading Literacy Study in Primary Schools in 40 Countries (TIMSS \& PILS International Study Center, Chestnut Hill, MA 02467).

Narvaez, D. (2002). Individual differences that influence reading comprehension. In C.C. Block \& M. Pressley (Eds.), Comprehension instruction: Research-based best practices (pp. 158-175). New York: Guilford.

Nuttall, C. (1996). Teaching Reading Skills in a Foreign Language. Portsmouth, NH: Heinemann.

Ozer, O. (2004). Constructivism in Piaget and Vygotsky. Retrieved from http://www.fountainmagazine.com/Issue/detail/CONSTRUCTIVISM-in-Piaget-and-Vygotsky

Pardo, L. S. (2004). What every teacher needs to know about comprehension. International Reading Association (pp. 272-280). https://doi.org/10.1598/RT.58.3.5

Park, H. (2016). Education. Retrieved from January 4,2016.From http:/highered.mheducation.com/sites/0072820144/student_view0/chapter9/index .html.

Petscher, Y. (2010). A Meta-analysis of the Relationship between Students, Attitude towards Reading and Achievement in Reading. Journal of Research in Reading, 33(4), 335-355. https://doi.org/10.1111/j.1467-9817.2009.01418.x

Philippine Statistics Authority. (2013). 2013 FLEMMS Functional Literacy, Education and Mass Medid Survey Final Report. Manila, Philippines May, 2015.

Pilayan, J. S. (2014). Correlation on Hemispheric dominance and Reading Comprehension of Freshmen Secondary Students (Unpublished thesis, University of the Visayas, Cebu City. Philippines).

Pressley, M. (2006). Reading Instruction that Works: The Case for Balanced Teaching. New York, USA: Guilford.

Rathe, B., \& Blankship, L. (2005). Recreational Reading Collections in Academic Libraries. Collection Management, 30(2),78-85. 


\section{Macrothink}

Journal of Asian Development

ISSN 2377-9594 2017, Vol. 3, No. 2

Rumelhart, D. (1980). "Schemata: The building blocks of cognition." In Theoretical Issues in Reading and Comprehension. In R. Spiro, B. Bruce, and W. Brewer (Eds.), An interesting and influential argument that schema may represent the basic units of everyday knowledge in cognitive systems, (pp. 33-58). Hillsdale, NJ : Lawrence Erlbaum .

Rundell, M. (2008). Schema Theory. Retrieved from February 3, 2016. From http://www.csus.edu/indiv/g/gipej/teaparty.pdf.

Seitz L. (2010). Students' attitudes toward reading: A case study. Journal of Enquiry and MTCN in Education, 3(2). from https://journal.buffalostate.edu/index.php/soe/article/viewfile/107/33.

Shabani, K., Khatid, M., \& Ebadi, S. (2010). Vygotsky's Zone of Proximal Development: Instructional Implications and Teachers' Professional Development. English Language Teaching. 3(4).

Shera, P. (2014). School Effects, Gender and Socioeconomic Differences in Reading Performance: A Multilevel Analysis. https://doi.org/10.5539/ies.v7n11p28

Sliwka, C. (2008). Connecting to History Through Historical Fiction. Language Arts Journal of Michigan, 23(2), 11. https://doi.org/10.9707/2168-149X.1125

Southeast Asian Ministers of Education Organization. (2012). K to 12 Toolkit. Quezon City, Philippines.

Sunderland, J. (2000). Issues of language and gender in second and foreign language education. Language Teaching, 33, 203-223. https://doi.org/10.1017/S0261444800015688

Villamin, A. M., Diaz, L. S., Talens, B. A., \& Santos, N. S. (2001). Gateways and Skyways to Developmental Reading. Quezon: Katha Publishing.

Wolf, D. (1993). A comparison of assessment tasks used to measure FL reading comprehension. Modern Language Journal, $\quad 77, \quad 473-89$. https://doi.org/10.1111/j.1540-4781.1993.tb01995.x

\section{Copyright Disclaimer}

Copyright for this article is retained by the author(s), with first publication rights granted to the journal.

This is an open-access article distributed under the terms and conditions of the Creative Commons Attribution license (http://creativecommons.org/licenses/by/4.0/). 